\title{
An Ecological Analysis of the Role of Role-play Games as Affordances in Iranian EFL Pre- university Students' Vocabulary Learning
}

\author{
Mansoor Fahim \\ Islamic Azad University, Science and Research Branch, Tehran, Iran \\ Email: dr.manfahim@yahoo.com \\ Somayyeh Sabah \\ Islamic Azad University, Science and Research Branch, Tehran, Iran \\ Email: somayyehsabah@yahoo.com
}

\begin{abstract}
The present study was intended to yield an ecological analysis of the role of role-play games on the degree of vocabulary learning and recall of the Iranian EFL pre-university students. To this end, forty students randomly selected from a range of pre-university students took part in an experiment. They were equally divided into the experimental and control groups. The control subjects received no treatment, whereas the experimental participants were assigned the responsibility of engaging in one role-play game after the teaching of the new vocabulary introduced in each lesson. Then, a 40-item vocabulary test was administered as a final teacher-made achievement test. The statistical $t$ test results that were carried out with the SPSS Software indicated that there was a significant difference between the degree of the experimental participants' acquisition and recall of the vocabulary items as compared with the control participants' vocabulary recall performance. This was theoretically justified regarding the debates on the affordance of both activity and agency in the role-play gaming that accordingly augmented the degree of the experimental subjects' further engagement.
\end{abstract}

Index Terms — engagement, affordance, niche, role-play games, and vocabulary recall

\section{INTRODUCTION}

As Gallo-Crail and Zerwekh (2002, as cited in, Khuvasanond, Sildus, Hurford, \& Lipka, 2010) put it, a hallmark of effective strategies for teaching English as a Second Language (ESL) and English as a Foreign Language (EFL) involves assisting students to comprehend and communicate utilizing the appropriate function of words. According to Huyen and Nga (2003), Asian students may regard the process of learning the second language vocabulary items as a list of new words that they must associate with their native language meaning without any further real practices that engross a real-life context. However, this strategy can inhibit the learning of correct word meanings.

Accordingly, as Redd and Schmidt-Crawford (2011) put it, recent studies call for using games for vocabulary learning since they are said to provide a way for words to be presented in an organized manner that can extend the school day and amount of time spent working in a content area. That is to say, vocabulary-enriched games might provide the extra support for learners to achieve success and build their vocabulary word bank.

\section{A. Statement of the Problem}

In view of the foregoing, the present study was intended to analyze the impact of utilizing role-play games on the degree of vocabulary learning and recall performance of Iranian EFL pre-university students. The foremost aspiration was to probe into the affordance features that the role-playing games could offer to EFL students in the classroom environment.

\section{B. Gap of Research in the Domain of the Study}

Although the significance of learning vocabulary through the use of communicative activities, particularly games has been acknowledged in the recent agenda of literature on activity-based approaches (e.g., Cornillie, Jacques, De Wannemacker, \& Paulussen, 2010; Redd \& Schmidt-Crawford, 2011; Huyen \& Nga, 2003; Wang, Shang, \& Briody, 2011), to name a few among others, it seems that not many research projects can be found on the impact of role-play games on the Iranian EFL pre-university students' vocabulary learning and recall. Accordingly, the present study aspired for filling in the gap in this domain of the study.

\section{Research Questions}


In the light of the foregoing, the present study was essentially determined to mull over the subsequent research questions:

1. What is the impact of utilizing role-play games on Iranian EFL pre-university students' vocabulary learning?

2. Does the use of role-play games enhance the Iranian EFL pre-university students' recall of the vocabulary items?

3. How do role-play games augment the Iranian EFL pre-university students' learning and recall of vocabulary items?

\section{Research Hypotheses}

Theoretically, it was hypothesized that the Iranian EFL pre-university students might gain a greater degree of command over the vocabulary items in each lesson through practicing them in role-play games. Therefore, it was conjectured that the exploitation of role-play games would enhance their learning of vocabulary as well as their vocabulary recall performance.

\section{E. The Significance of the Study}

Basically, the present study is considered to be significant in the instructional context of teaching English language to Iranian EFL learners in certain respects. In the first place, it strives to draw attention to the imperative impact of the exploitation of fine arts, in general, and role-play games, in particular, in the local, pedagogical context of foreign language learning, which at this juncture refers to the component of vocabulary learning and recall. Second, it has recourse to the ecological perspective towards the process of foreign language learning in that it treats the role-play activities in terms of engagement and affordance rather than triggering bits of input. What is more, the present study strives to redefine games from an ecological point of view that may be somewhat different from the traditional definitions given for the term game in the theoretical pedagogical literature.

\section{REVIEW OF LITERATURE}

Drawing on an ecological perspective towards Second Language Acquisition (SLA), Van Lier (2000) argues that the learner is immersed in an environment resplendent with certain potential meanings. These meanings become available progressively as the learner acts and interacts within and with this environment. Van Lier (2000, pp. 246-247) holds that "learning is not a holus-bolus or piecemeal migration of meanings to the inside of the learner's head, but rather the development of increasingly effective ways of dealing with the world and its meanings." Therefore, to search for learning is to take a look at the active learner in her or his environment, not at the contents of her or his brain.

\section{A. The Concept of Affordance}

The word affordance is coined by the psychologist Gibson (1979, as cited in, Van Lier, 2000) to make reference to a reciprocal relationship between an organism and a particular feature of its environment. Drawing on the Chaos and Complexity Theory (C\&CT), Van Lier $(1996,2000)$ investigates the full complexity and interrelatedness of processes that are combined to produce an environment. Van Lier (1996) shifts the focus in language learning from input to engagement debating that there is a problem regarding the input view of language learning since it considers language as a fixed code and learning as a process of reviewing and processing the so-called fixed code.

Van Lier (2000) then explores the notion of affordance as an alternative to input and presents the argument that an affordance is a particular property of the environment that is relevant to an active, perceiving organism in that environment. An affordance affords further action; however, it does not cause or trigger it. What becomes an affordance is dependent upon what the organism performs, what it yearns for, and what is constructive for it. Putting it this way, if the language learner is active and engaged, she or he is likely to perceive linguistic affordances and to bring them into play for the linguistic action. Van Lier (2000, p. 246) defends that "from an ecological perspective, the learner is immersed in an environment full of potential meanings. These meanings are available gradually as the learner acts within and with the environment."

In the light of the foregoing, Van Lier (2000) analogizes Gibson's (1979, as cited in, Van Lier, 2000) ecological psychology with the work of Vygotsky's (1978, 1986) Sociocultural Theory (SCT), Bakhtin's (1981, 1986) dialogic imagination, and their respective followers as the unit of analysis is not the perceived object or the linguistic input; rather, the active learner and the activity in its own right are highlighted. As Van Lier (2004a) puts it, the major characteristics of ecology comprise relationships rather than objects, context, emergent patterns, quality, value, critical perspectives, variability, diversity, and agency. Van Lier (2004, p. 91) highlights the key notions in the definitions given for affordance, namely relations, possibility, opportunity, immediacy, and interaction. For him, action, perception, and interpretation, in a continuous cycle of mutual reinforcement, are the preconditions for the emergence of meaning.

From the perspective of Van Lier (2010), an ecological approach aims to look at the learning process, the actions, and activities of teachers and learners, the multilayered nature of interaction and language use, in all their complexity and as a network of interdependencies among all the elements in the setting, not only at the social level, but also at the physical and symbolic levels. According to Van Lier (2010), multiple relationships are established in and among the physical, social, and symbolic worlds in human ecosystems and language functions to set up, preserve, and enlarge such relationships. The world is replete with opportunities that grant access to plentiful affordances to engage in activities of 
various kinds. Affordances are identified in terms of relationships of possibility; that is to say, they make action, interaction, and joint projects possible.

\section{B. Affordance and Scaffolding in ZPD}

Vygotsky (1978) explores the child's development, and how it is conducted by the role played by culture and interpersonal communication. The key premise of Vygotskyan psychology is the concept of the cultural mediation. According to Vygotsky (1978, p. 57), “every function in the child's cultural development appears twice: first, on the social level, and on the individual level; first between people (interpsychological), and then inside the person (intrapsychological)." This process is referred to as internalization.

Among the concepts put forward by Vygotsky (1978), two are conceived to be of fundamental import within the realm of SLA, i.e., ZPD and scaffolding. Vygotsky's $(1978,1986)$ Sociocultural Theory (SCT) regards interaction as the bedrock of the process of language acquisition. To explain the relationship between the interpersonal plane and the intrapersonal plane, Vygotsky (1978, p. 86) develops the concept of the Zone of Proximal Development (ZPD), which he defines as "the distance between the actual developmental level as determined by independent problem solving and the level of potential development as determined through problem solving under adult guidance or in collaboration with more capable peers."

The second notion regards this provision of help, which should be gradually withdrawn as the learner gets autonomy over the task, and it is what Vygotsky (1978) refers to as scaffolding. The concept of scaffolding, further elaborated on by Bruner (1985, as cited in, Saville-Troike, 2005) refers to the verbal guidance that an expert provides to help a learner perform any specific tasks, or the verbal collaboration of peers to perform a task, which appear to be too difficult for any one of them individually. The metaphor of scaffolding is also extended by Donato (1994, p. 40), who holds that "in social interaction a knowledgeable participant can create, by means of speech, supportive conditions in which the novice can participate in, and extend, current skill and knowledge to higher levels of competence."

As Saville-Troike (2005) puts it, scaffolding is not something that happens to a learner as a passive recipient; rather, it happens with a learner as an active participant. From the perspective of Obukhova and Korepanova (2009), the ZPD concept is seen as the scaffolding, namely the structure of support points for performing an action.

In view of the foregoing, Lantolf and Thorne (2006) debate that the individual development is both afforded and constrained by the ZPD. That is to say, the capacity to profit from different kinds of interaction and scaffolding within the ZPDs leads to accomplish a particular activity, a point also acknowledged by Ziglari (2008).

\section{The Concept of Niche}

Closely related to the concept of affordance is the concept of the niche. According to Polechová and Storch (2008, p. 1088), "ecological niche characterizes the position of a species within an ecosystem, comprising species habitat requirements as well as its functional role." Ecological niche incorporates each and every one of the interactions between a species and the biotic and abiotic environment, and, therefore, embodies an incredibly essential and basic ecological concept. Polechová and Storch (2008) make a distinction between three approaches to niche, i.e., niche as the description of a species' habitat requirements; niche as the ecological function of the species, and niche as a species position in a community or the formalization of ecological niche concept. In an attempt to understand these approaches in relation to language learning, Paiva (2011) translates these approaches as niche as an environment mediated by language, niche as a place to act in by using the language, and niche as a language user position in a discourse community respectively.

\section{Affordance in ESL/ESL Niches}

In the light of the foregoing, Paiva (2011) draws on the ecological perspective that in order to gain success, a learner must make a living in her/his niche. The student has to coexist with other learners and occasionally struggle for her/his position in the niche, mainly when one is in a classroom environment. In addition, the resources usually available in a classroom are inadequate for successful language acquisition. Learners must search for affordances beyond the classroom and not all of them will be able to perceive the affordances or make the most of all the ones offered by the environment.

According to Paiva (2011), one makes use of language to think, to perceive, and interpret the linguistic social actions around her or him and to take action in her or his niches. In the case of foreign language learning, a kind of affordance, which has an immense impact on the learners, is how they relate to that language; that is to say, how they perceive the language they learn. A second or other language can be viewed as a dominating instrument, as a tool or artifact for communication, as a cultural production mediator, as an instrument that opens windows for business, as something of high or low prestige, and so on.

To put it simply, Paiva (2011) argues that taking into account the idea of the first type of niche as an environment mediated by language, English language learners must belong to a habitat, wherein they can find language affordances. In EFL niches, language affordances are not the identical for each learner. There are contexts, which offer supplementary opportunities for language learning and fewer constraints than others and vice-versa.

In exploring the second type of niche in ESL/EFL contexts, Paiva (2011) holds that the majority of the students perceive language affordance as they speak it; however, numerous teachers perceive it as describe it or talk about it. The 
students' concept of what a language might be is not commensurate with their teachers' own concept. In spite of their niches, which apparently proffer poor English language affordances, many learners bridge the gaps by looking for affordances beyond the classrooms and meet the second concept of niche, niche as a place to act in by using the language.

According to Paiva (2011), the third type of niche is that of niche as a language user's position in a discourse community. A learner who presupposes the position of a language user is expected to be successful in her or his attempt to learn the language. Despite these arguments, Paiva (2011) argues that language affords a variety of uses, singing, chatting, reading, writing, listening, and so forth; however, a number of teachers insist on focusing only on the formal aspects of the language.

\section{E. On Games in SLA}

In view of the foregoing lines of argument, Sánchez, Morfín, and Campos (2007) bring to mind the numerous definitions given for game, while arguing that most of these look similar in that not many of them delineate a game as a practical tool or constructive resource for teaching. Looking at the miscellaneous definitions given for the game, Sánchez, Morfín, and Campos (2007) come across common similarities amongst them and debate that they all coincide principally in three aspects, namely competition, rules, and enjoyment.

As said by Sánchez, Morfín, and Campos (2007), the term competition in its own right signifies the foremost component that an interactive activity should encompass so as to be conceived of as a game. Competition interactive games build up the student's motivation, as they are constantly engaged in the daily competition. Nevertheless, teachers need to be careful when making the students competitive for the reason that it may bring about affecting feelings of inadequacy. Consequently, this component should be skillfully managed in the class. One way that teachers can achieve this is by the use of rules.

Based on the argument by Sánchez, Morfín, and Campos (2007), rules set up the patterns and codes wherein the game should be played, teachers may be responsible for making students follow the rules. Thus, the teacher can readily keep control of the class while students get pleasure from and follow the logic of the game and play it suitably, achieving at the same time the goals of the activity effectively.

Sánchez, Morfín, and Campos (2007) muse that though the word enjoyment has been explained in diverse ways, this term is regarded as an imperative component for increasing students' motivation in learning a language. Students may enjoy the class, that way they might become more interested in it and obtain, in a better way, some further permanent knowledge to be used in the real life.

Based on the concepts previously analyzed, Sánchez, Morfín, and Campos (2007) present a fresh and refined definition of game that emerges within the field of pedagogy. A game is considered as a valuable technique, which comprises three chief elements, i.e., competition, rule(s), and enjoyment, which should be well established by a teaching-learning objective. Any teacher is capable of making use of games in order to augment the student's motivation towards the English language, at the same time that students can better develop or improve his/her own abilities of learning. Such is the purpose that the use of dynamic games has in class.

\section{F. General Benefits of Games}

In principle, Carrier (1980, as cited in, Sánchez, Morfín, and Campos, 2007) believes that games are incredibly valuable in a class since they provide an opportunity for students to bring into play their language in a less formal context of situation, devoid of the pressure of doing it absolutely correctly or not, but with the enthusiasm for winning the game, as well as practicing the language.

As Carrier (1980, as cited in, Sánchez, Morfín, and Campos, 2007) puts it, there are three appropriate stages in a lesson where games can be used; that it, they can be drawn on as an introduction, after the development of the class, and at the end of the class. When games are utilized as an introduction, they are firstly exploited to open up the class in a stimulating way. At this juncture, the teacher gets students' interest in the language from the very beginning of the class. Besides, they are used to know what point or level students already have. Therefore, the game is taken as a review of a previous activity. In addition, games are exploited after the development of the lesson to reinforce an item that the teacher considers necessary to review and/or to practice. Games brought into play at the end of the class serve to close lessons in a stimulating way. Thus, students can have some practice of the item studied, and the teacher can realize if the item is well achieved by students.

According to Sánchez, Morfín, and Campos (2007), games should be positive at any moment they are incorporated as this makes students take pleasure in the activity while they are having a hidden helpful practice. Furthermore, hidden is mentioned because this kind of activities more often than not make students forget they are learning, and they concentrate more on playing and/or winning.

In taking account of the uses of games in language classrooms, Lengeling and Malarcher (1997) categorize the benefits of games into four domains, i.e., affective filter, cognitive functioning, class dynamics, and adaptability.

As far as the affective filter is concerned, Lengeling and Malarcher (1997) argue that the games lower the affective filter, inspire the creative and spontaneous use of language, endorse communicative competence, motivate the students, and provide the students with the opportunity of learning the language through fun. 
With respect to the immense impact of games on the students' higher mental and cognitive development, Lengeling and Malarcher (1997) believe that they reinforce the cognition, review and extend the cognitive ability, and gear the students' attention on grammar communicatively.

From the perspective of Lengeling and Malarcher (1997), the augmentation of the class dynamics through the use of games is realized in terms of certain features; that is to say, they are student centered, and teacher acts only as facilitators. Besides, games are conceived to construct the class cohesion, cultivate the whole class participation, and endorse the healthy competition.

As said by Lengeling and Malarcher (1997), adaptability is made possible by means of games as they are easily adjusted for age, level, and interests. Additionally, they make the most of all four skills and necessitate the minimum preparation after development.

In view of the foregoing, Wang (2010) summarizes the characteristics of Communicative Language Teaching (CLT) and expects that the use of communicative tasks and activities such as games play a crucial role in Communicative Approach (CA) to language teaching and learning as learners can go beyond the mastery of structures to communicate meanings in real-life contexts of situations. In particular, communicative activities in the form of games create a context where learners are engaged in the use of the target language to negotiate meanings, share information, and interact with others within. For Wang (2010), games possess certain features that may satisfy the requirements of CLT, namely they motivate students' learning with fun, enjoyment, and excitement; supply chances to use language in authentic contexts; provide practice on language use and language usage; create an agreeable and supportive learning environment; and promote interpersonal relations.

\section{G. Classifications of Games}

As Tuan and Doan (2010) put it, classifying games into categories can be difficult because categories often overlap. In the first place, Hadfield (1999, as cited in, Tuan \& Doan, 2010) gives explanation for two ways of classifying language games. First, language games are divided into two types, i.e., linguistic games and communicative games. Linguistic games focus on accuracy, such as supplying the correct antonym. Communicative games focus on the successful exchange of information and ideas, such as two people identifying the differences between their two pictures, which are similar to one another but not exactly alike. The correct usage of language, though still significant, is secondary to achieving the communicative goal.

Second, Hadfield (1999, as cited in, Tuan \& Doan, 2010) classifies language games into many more categories. Together with the classification of games as linguistic games or communicative games, a number of games are observed to contain elements of more than one type, which comprise sorting, ordering, or arranging games; information gap games; guessing games; search games; matching games; labeling games; exchanging games; board games; and roleplay games.

\section{H. Role-play Games}

As said by Kodotchigova (2002, as cited in, Tuan \& Doan, 2010), the terms role play, drama, and simulation are sometimes utilized interchangeably; however, they can be distinguished. According to Tuan and Doan (2010), role-play games can engage students in playing certain roles that they do not play in the real-life situations, such as doctor, whereas in simulations students get involved in performing roles that they already play in real life or might be likely to play, such as a customer at a restaurant. Dramas are by and large scripted performances, while in role plays and simulations, students come up with their own words, although the preparation is often useful.

\section{Gaming and Vocabulary Learning: Role-plays}

The benefits of vocabulary learning through gaming techniques are indisputable. As Blachowicz and Fisher (2008, p. 50, as cited in, Redd \& Schmidt-Crawford, 2011, p. 57) put it, "games and word play can provide a context in which students can enjoy word learning and develop word consciousness." Accordingly, Wang, Shang, and Briody (2011) argue that based on previous studies, utilizing games to teach young learners can augment students' motivation, confidence, and vocabulary acquisition. Due to the advantages of challenging content, it is easier to capture their attention than with traditional teaching. In what follows, the effects of role-play games on the EFL students' vocabulary learning and recall are empirically examined and then theoretically discussed.

\section{Methodology and ReSEARCh Design}

The present study was intended to look at the impact of using role-play games on the vocabulary learning and vocabulary recall performance of Iranian EFL pre-university students. In so doing, an experiment was carried out. The experimental design of the research project has been explicated below.

\section{A. Participants}

A total of forty Iranian EFL pre-university students participated in this experiment. They were indiscriminately selected from a range of female students at Raziyyeh Pre-university School. In order to perform the experimental project, equal numbers of participants were randomly divided into two groups, namely group (EG) known as the Experimental Group and group (CG) that refers to the Control Group. The Experimental subjects were further divided 
into five sub-groups called (A), (B), (C), (D), and (E). The students in both groups were asked to conceive of the researcher as the receiver of their performances.

\section{B. Materials}

The students in the each of the experimental groups of (A), (B), (C), (D), and (E) were required to work on a roleplay on the basis of the new vocabulary items introduced at the end of the lessons one, two, three, four, and five in the English book for Iranian EFL pre-university students. Thus, they were asked to make use of these words in their roleplay performances.

\section{Instruments}

Two kinds of instruments were utilized in the present study. The first instrument applied in this study was a 40-item vocabulary test administered as a final teacher-made achievement test. The test was conducted after the five treatment sessions and lasted for forty minutes to analyze the impact of utilizing role-play games on the degree of the experimental participants' acquisition and recall of the vocabulary items taught in each session as compared with the control participant' vocabulary recall performance. Secondly, the Statistical Package for Social Sciences (SPSS) software was exploited to fulfill the statistical analyses.

To this end, the mean scores obtained for the performance of each group were compared through the use of the twotail, independent $t$ test procedure. In order to fulfill the quantitative assessments, the statistical analyses were practically carried out on the basis of the comparison of the calculated score obtained from the difference between the two mean scores attained from the administered test and the critical $t$ score. It is worth stating that the critical $t$ score and the level of significance (the level of $\alpha$ ) were constant across the numerical analyses; that is, the critical t score equaled 3.040 as $\alpha$ was assumed 0.01 . Therefore, the $\mathrm{p}$ value was assumed $\leq 0.01$. Since the independent $\mathrm{t}$ test was a two-tail one due to the autonomous participation of forty subjects equally divided into the experimental and control groups, $\alpha$ was divided by two, which equaled 0.005. In addition, the degree of freedom (df) was assumed 19.

\section{Procedure}

To analyze the impact of role-play games on the vocabulary acquisition and vocabulary recall performance of Iranian EFL pre-university students, the subsequent procedures were followed. The subjects taking part in the control group received no treatment, whereas the experimental participants in each sub-group received role-play games as a treatment. Each sub-group was assigned the responsibility of engaging in one role-play game after the teaching of the new vocabulary introduced in each lesson. Therefore, five role plays were performed during treatment sessions. Each roleplay game lasted for ten to fifteen minutes. Mentioned should be of the point that the conditions plus the teaching method as well as the teacher was the same for both groups.

\section{RESULTS AND DISCUSSION}

Technically, the statistical results obtained from the final achievement test of vocabulary are observed to reveal remarkable findings that are worth considering. The experimental group is conceived to gain the mean score of 15.1 while the control group is viewed to achieve the mean score of 12.7. The succeeding tables exhibits that the participants have performed differently.

TABLE 1

PAIRED SAMPLES STATISTICS

\begin{tabular}{|l|l|l|l|l|l|}
\hline & & Mean & N & Std. Deviation & Std. Error Mean \\
\hline \multirow{2}{*}{ Pair 1 } & Control & 12.7000 & 20 & 2.65766 & .59427 \\
\cline { 2 - 7 } & Experimental & 15.1000 & 20 & 2.80788 & .62786 \\
\hline
\end{tabular}

TABLE 2

PAIRED SAMPLES CORRELATION

\begin{tabular}{|l|l|l|l|l|}
\hline & & $\mathrm{N}$ & Correlation & Sig. \\
\hline Pair 1 & Control and Experimental & 20 & .166 & .483 \\
\hline
\end{tabular}

TABLE 3

PAIRED SAMPLes Test

\begin{tabular}{|c|c|c|c|c|c|c|c|c|}
\hline \multirow{4}{*}{ Pair 1} & \multicolumn{5}{|c|}{ Paired Differences } & \multirow[b]{3}{*}{$\mathrm{t}$} & \multirow[b]{3}{*}{$\mathrm{df}$} & \multirow[b]{3}{*}{ Sig. (2-tailed) } \\
\hline & \multirow[b]{2}{*}{ Mean } & \multirow[b]{2}{*}{ Std. Deviation } & \multirow[b]{2}{*}{ Std. Error Mean } & \multicolumn{2}{|c|}{$\begin{array}{l}95 \% \text { Confidence Interval of the } \\
\text { Difference }\end{array}$} & & & \\
\hline & & & & Lower & Upper & & & \\
\hline & -2.40000 & 3.53032 & .78940 & -4.05224 & .74776 & -3.040 & 19 & .0007 \\
\hline
\end{tabular}


In the light of foregoing results, it is evident that the difference between the mean score obtained for both groups is significant since the $\mathrm{p}$ value equals $0.007<0.01$. As a result, it is generally assumed that there exists a significant discrepancy between the performances of the two groups. Basically, the close examination of the numerical analyses reveals the notorious impacts of the role-play games on the experimental participants' recall of vocabulary items. The subsequent lines of argument are meant to yield further conjectural justifications for the obtained results.

Critically, the statistical results of the present study indicate that the proper utilization of communicative games, in general, and role-plays games in the local contexts of the argument under discussion does have a significant impact on the amount and degree of the vocabulary learning and recall of Iranian EFL pre-university students. The foregoing statistical results can be further theoretically justified with respect to the debates on the affordance of both activity and agency in the instructional context of situation.

\section{A. Role-play Games and the Affordance of Activity}

Van Lier (2004b) points out that activity and perception form one whole or a necessary unity. To perceive, one must act; to act, one must perceive. Activity in one's environment brings into being the affordances in those environments that are relevant to the agent. With respect to language learning, this means an activity-based approach, in which what is structured in the curriculum are the activities and not the language. In such an activity-based curriculum language surrounds the learner in all its richness and complexity.

As said by Van Lier (2004b), instead of being presented with input, which is structured in one way or another, learners are recommended pick up the linguistic information they need for their activities, so long as access is provided. The provision of access can be done through scaffolding, i.e., by assisting learners in how and where to look, by providing opportunities for interaction and collaboration with peers, and by structuring tasks so that they have clear procedures and goals, while at the same time allowing for learners to employ creativity in a context of growing autonomy.

In view of the foregoing, the results of the present study pinpoint that the games, in general, and, in the local context of this argument, the role-play games, in particular, may present the EFL learners with affordance through the provision of activity-based practices rather than triggering the input piecemeal. Such games are said to proffer scaffolding to the subject agents through assistance, interaction, and collaboration in their ZPDs.

\section{B. Role-play Games and Affordance of Agency}

To put it in plain words, Van Lier (2010) defines agency as the movement of the organism moving in order to live and grow, a change of state or direction, or even a lack of movement where movement is expected. Movement can be cast in literal as well as in figurative ways. Agency is, therefore, an essential concept in learning, at many levels and in many manifestations. It is a further general and more reflective concept than the closely related terms autonomy, motivation, and investment. In other words, autonomy, motivation, and investment are in a sense products or manifestations of a person's agency.

According to Van Lier (2010), a wholly and entirely passive learner will not learn. A compliant, obedient, or dutiful learner is said to learn for the reason that she or he makes use of agency if only at the behest of others. In this way, learners who study a foreign language in schools, as it is required, will be capable of having certain degrees of success to pass tests. However, in order to make significant progress and to make permanent strides in terms of setting objectives, pursuing goals, and moving towards the lifelong learning, learners need to make choices and employ agency in more self-directed ways.

For Van Lier (2010), learning is inseparably tied to agency. The exploitation of agency depends on a learningconducive environment that allocates and instigates a multiplicity of manifestations of agency at different levels. Not all types of agency are cut of the same cloth. It can be more individual or more social, more creative or more routine, more serious or more playful, and so on and so forth. There must be room in a learning environment for an assortment of expressions of agency to flourish. The creation of such an environment is a major task of pedagogy. Once this task is understood, the agency-rich environment can become the joint project of teachers and learners alike.

Interpreting the results of this study in the light of the preceding lines of debate, it is inferred that games and specifically role-play games may provide the EFL learners with agency-rich environments. This point is elucidated regarding the learners' active movements, motivation, and autonomy through the accomplishment of activity-based games, wherein, to draw on Storch's (2002, as cited in, Clark \& Clark, 2008) terminology, the observed pattern of interaction is that of greater degrees of high equality in terms of the division of power, authority, and control over the task plus the further degrees of high mutuality in terms of their engagement between each others' contributions.

\section{Redefining Games from an Ecological Perspective}

Drawing on the three ecological approaches to the concept of niche as explicated by Polechová and Storch (2008), namely niche as the description of a species' habitat requirements; niche as ecological function of the species, and niche as a species position in a community or the formalization of ecological niche concept along with Paiva's (2011) threedimensional translation of these approaches in EFL learning environments, the present study strives to proffer a redefinition of the games in the theoretical literature that is, to a greater or lesser degree, different from the traditional 
perspectives. From an ecological point of view, games are redefined as niches replete with language affordances that the agent language users occupy to operate on its functions and activities.

\section{Pedagogical Implications}

Drawing on an ecological approach to language teaching and learning, the present study offers certain pedagogical implications for teaching vocabulary to EFL students. In the first place, it pays much attention to the development of mutual co-operation, fluidity, openness, and the active exchange of information in the in the EFL classrooms. Contrary to the traditional assumptions, the Communicative Approach (CA) to Second Language Acquisition (SLA) is observed to require the subjects to draw on their prior knowledge, reveal background information about the content, and strive to take part in communicative interactions.

Second, considerable emphasis is placed on the point that SLA, in general, and the vocabulary learning, in particular, are essentially communicative processes, which inspire the students' co-operations and dynamic performances and pose somewhat alarming problems for many who still put their entire reliance on the formal teaching of grammatical rules or individual lexical items isolated from the real-life contexts of situations. In addition, it draws attention to the significance of learning English in the EFL context through fun and enjoyment by encouraging the learners to investigate the language through the process of meaningful interaction.

\section{CONCLUSION}

In due course, the present study has been intended to explore the impact of the exploitation of role-play games on the Iranian EFL pre-university students' vocabulary learning and recall. The quantitative analyses have indicated that the positive effects of role-play games in learning and recalling vocabulary items. Based on the findings of the present study, it appears that games conform to the affordance features advocated in the ecological approach to SLA advocated by Van Lier $(1996,2000,2004 a, 2004 b, 2010)$ in that they are observed to help the students gain agency in accomplishing the gaming activities.

Despite the advantages of games in teaching and learning vocabulary, the teachers are recommended bring to mind Huyen and Nga's (2003) words of caution that although the role of games in teaching and learning vocabulary cannot be denied, in order to attain the most from vocabulary games, it is necessary to select suitable games for the EFL students. Whenever a game is to be conducted, the number of students, their levels of proficiency, cultural background, timing, learning topic, and the classroom environments are essential factors that need to be taken into account.

\section{Suggestions for further research}

In view of the significance of the critical scrutiny resting on the role of games in the instructional milieu of teaching EFL, it is recommended perform further investigations in analyzing the impact of role-play games on the teaching and learning of grammar. Besides, the comparative study of the EFL students' degree of the acquisition of both vocabulary and grammar with respect to other communicative games, say, simulations and dramatizations, or other types of games used for learning vocabulary, which enable the results to be triangulated is supposed to be of significance in this domain. What is more, the investigation of the effect of the exploitation of role-play games on the EFL learners' use of the instructed vocabulary in the real-life contexts of situations might be also beneficial.

\section{REFERENCES}

[1] Bakhtin, M. M. (1981). The dialogic imagination: Four essays. Austin, TX: University of Texas Press.

[2] Bakhtin, M. M. (1986). Speech genres and other late essays. Austin: University of Texas Press.

[3] Clark, C. T., \& Clark, I. (2008). Exploring and exposing a gap in L2 research: How socio-linguistic roles facilitate or frustrate second language acquisition. Journal of the Spanish Association of Anglo-American Studies, 30(1), 101-113.

[4] Cornillie, F., Jacques, I., De Wannemacker, S., \& Paulussen, H. (2010). Vocabulary treatment in adventure and role-playing games: A playground for adaptation and adaptivity. Paper presented at the 4th meeting of the Flemish chapter of the digital game research association, MICT, Ghent IBBT, University. http://www.bobdeschutter.be/digra/data/files/Papers/Frederik_Cornillie-040610-Presentatie.pdf (accessed 07/10/2011)

[5] Donato, R. (1994). Collective scaffolding in second language learning. In J. P. Lantolf \& G. Appel (Eds.), Vygotskyan approaches to second language research (pp.33-56). Norwood, N.J.: Ablex.

[6] Hadfield, J. (1999). Beginners' communication games. Harlow, Essex: Longman.

[7] Huyen, N. T. T., \& Nga, K. T. T. (2003). Learning vocabulary through games: The effectiveness of learning vocabulary through games. http://www.asian-efl-journal.com/dec_03_vn.pdf (accessed 07/10/2011)

[8] Khuvasanond, K., Sildus, T. I., Hurford, D. P., \& Lipka, R. P. (2010). Comparative approaches to teaching English as a second language in the United States and English as a foreign language in Thailand. http://www.lscac.msu.ac.th/book/175.pdf (accessed 07/10/2011)

[9] Lantolf, J. P., \& Thorne, S. L. (2006). Sociocultural theory and the genesis of second language development. Oxford: Oxford University Press.

[10] Lengeling, M. M., \& Malarcher, C. (1997). Index cards: A natural recourse for teachers. Forum, 35(4), 42. http://eca.state.gov/forum/vols/ (accessed 07/10/2011)

[11] Obukhova, L. F., \& Korepanova, I. A. (2009). The Zone of Proximal Development: A Spatiotemporal Model. Journal of Russian \& East European Psychology, 47(6), 25-47. doi: 10.2753/RPO1061-0405470602 (accessed 07/10/2011) 
[12] Paiva, V. L. M. O. (2011). Affordances beyond the classroom. In P. Benson \& H. Reinders (Eds.), Beyond the classroom: The theory and practice of informal language learning and teaching (pp. 59-71). Palgrave: Macmillan.

[13] Polechová, J., \& Storch, D. (2008). Ecological niche. In S. E. Jorgensen \& B. Fath (Eds.), Encyclopedia of ecology (pp. 10881097). Oxford: Elsevier.

[14] Redd, J., \& Schmidt-Crawford, D. (2011). The potential for building high-school students' vocabulary using an iPod touch and gaming App. Journal of Open, Flexible, and Distance Learning, 15(2), 55-67. http://journals.akoaotearoa.ac.nz/index.php/JOFDL/article/view/50/44 (accessed 07/10/2011)

[15] Sánchez, M. M. M., Morfín, A. P., \& Campos, V. E. P. (2007). Interactive games in the teaching-learning process of a foreign language. Teoría y Praxis, 4, 47-66.

[16] Saville-Troike, M. (2005). Introducing second language acquisition. Cambridge: Cambridge University Press.

[17] Tuan, L. T., \& Doan, N. T. M. (2010). Teaching English grammar through games. Studies in Literature and Language, 1(7), 61-75.

[18] Van Lier, L. (1996). Interaction in the language curriculum: Awareness, autonomy, and authenticity. New York: Longman.

[19] Van Lier, L. (2000). From input to affordance: Social-interactive learning from an ecological perspective. In J. P. Lantolf (Ed.), Sociocultural theory and second language learning: Recent advances (pp. 245-259). Oxford: Oxford University Press.

[20] Van Lier, L. (2004a). The ecology and semiotics of language leaning: A sociocultural perspective. Boston: Kluwer Academic Publishers.

[21] Van Lier, L. (2004b). The semiotics and ecology of language learning: Perception, voice, identity, and democracy. Utbildning and Demokrati, 13(3), 79-103.

[22] Van Lier, L. (2010). The ecology of language learning: Practice to theory, theory to practice. Procedia Social and Behavioral Sciences, 3, 2-6. doi: 10.1016/j.sbspro.2010.07.005

[23] Vygotsky, L. S. (1978). Mind in society: The development of higher psychological processes. Cambridge: Harvard University Press.

[24] Vygotsky, L. S. (1986). Thought and language. Cambridge: The MIT Press.

[25] Wang, Y. H. (2010). Using communicative language games in teaching and learning English in Taiwanese primary schools. Journal of Engineering Technology and Education, 7(1), 126-142.

[26] Wang, Y. J., Shang, H. F., \& Briody, P. (2011). Investigating the impact of using games in teaching children English. International Journal of Learning and Development, 1(1), 127-141. http://dx.doi.org/10.5296/ijld.v1i1.1118 doi: 10.5296/ijld.v1i1.118 (accessed 07/10/2011)

[27] Ziglari, L. (2008). Affordance and second language acquisition. European Journal of Scientific Research, 23(3), 373-379. http://www.eurojournals.com/ejsr.htm (accessed 07/10/2011)

Mansoor Fahim was born in Iran in 1946. He received a Ph.D. in TEFL (Teaching English as a Foreign Language) from Islamic Azad University in Tehran, Iran in 1994, an M.A. in General Linguistics from Tehran University in Tehran, Iran in 1978, and a B.A. in English Translation from Allameh Tabataba'i University in Tehran, Iran in 1975. As for his professional background, he was the chairman of the EFL department at Allameh Tabataba'i University from 2003 to 2007 and a member of the faculty of English Language and Literature at Allameh Tabataba'i University in Tehran, Iran from 1979 to 2008 when he was retired as an associate professor of TEFL. He has also taught English at a welter of universities and language schools. At present, he runs Psycholinguistics, Applied Linguistics, First and Second Language Acquisition, and Discourse Analysis courses at M.A. and Ph.D. levels at a number of universities in Iran, including Allameh Tabataba'i and Islamic Azad Universities. Moreover, he has several published articles and books mostly in the field of TEFL. Dr. Mansoor Fahim is currently a member of the editorial board of the Iranian journal of Applied Linguistic Studies, Sistan and Baloochestan University, Iran; Journal of Language Studies, Shahrekord University, Iran; and Journal of English Language Studies, Islamic Azad University, Tehran, Iran.

Somayyeh Sabah is an instructor of TEFL at Islamic Azad University. She did her B.A. and M.A. at Shahid Chamran University, Ahvaz, Iran. Currently, she is a Ph.D. candidate of TEFL at Islamic Azad University, Science and Research Branch, Iran, Tehran. She is active in teaching speaking and reading courses. Her areas of interest are Second Language Acquisition (SLA), Discourse Analysis, Critical Pedagogy, and Teaching Literature in TESOL. 